UCRL-ID-125265

\title{
The Degradation of TPX Components by Oxygen, Elevated Temperature, and Ionizing Radiation
}

\author{
Joseph C. Farmer
}

May 31, 1996

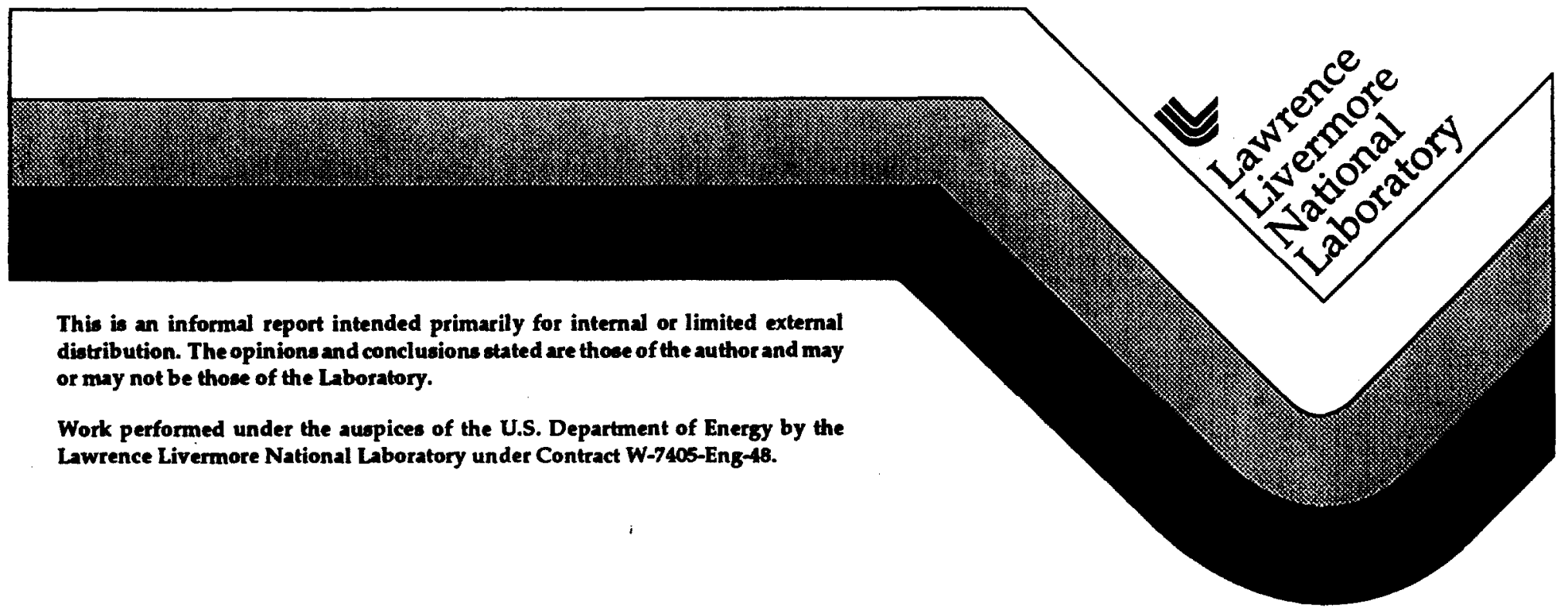




\section{DISClAIMER}

This document was prepared as an account of work sponsored by an agency of the United States Government. Neither the United States Government nor the University of California nor any of their employees, makes any warranty, express or implied, or sssumes any legal liability or responsibility for the accuracy, completeness, or usefulness of an information, apparatus, product, or process disclosed, or represents that its use would not infringe privalely owned rights. Reference herein to any specific commercial products, process, or service by trade name, trademark, manufacturer, or otherwise, does not necessarily constitute or imply its endorsement, recommendation, or favoring by the Unalted States Government or the Uaiversity of California. The viewsand opinions of authors expressed herela do not necessarily state or reflect those of the United States Government or the University of Calffornia, and shall not be used for advertising or product endorsement purposes.

This report has been reproduced directly from the best available cepy.

Available to DOE and DOE contractors from the Orice of Sclentific and Technical Information

P.O. Box 62, Oak Ridge, TN 37831

Prices available from (615) 576-8401, FTS 626-8401

Available to the public from the

National Technical Information Service

U.S. Department of Commerce

5285 Port Royal Rd.

Springield, VA 22161 


\title{
The Degradation of TPX Components by Oxygen, Elevated Temperature, and Ionizing Radiation
}

\author{
Joseph C. Farmer, Ph.D. \\ Chemistry and Materials Science Department \\ Lawrence Livermore National Laboratory \\ 7000 East Avenue \\ Livermore, California 84551 \\ Tel. 510-423-6574 \\ Fax. 510-423-2086 \\ E-mail: farmer4@llnl.gov
}

May 31, 1996

\section{Introduction}

Motivation. Poly(4-methyl-1-pentene), also known as PMP or TPX, has several commerciallyimportant characteristics such as high optical transparency, high crystalline melting point, low density, low electrical conductivity, and good heat resistance. Such characteristics have lead to numerous industrial applications including infrared windows, infrared lenses, membranes, and food packaging. The life components fabricated from this material may be limited by thermal oxidative and radiation-induced degradation. A preliminary review of the scientific literature has been conducted to obtain relevant information on the effects of oxygen, moisture elevated temperature, and radiation on the chemical, thermodynamic, mechanical, and electrical properties of this important construction material. Key information from the literature has become especially important in light of decreased budgets for defense-related research and development, and the prolonged service life of existing systems.

Synthesis. The synthesis of both PMP and its monomer are described by Lopez and Wilkes [1]. The monomer is produced by the dimerization of propylene using and alkali metal catalyst. Higher conversion and selectivity are obtained with potassium than with sodium. The temperature and pressure for the reaction are typically 1500 psig and 150 to $160^{\circ} \mathrm{C}$. The reaction occurs via an allyl carbanion $\left(\mathrm{K}^{+} \mathrm{CH}_{2} \mathrm{CH}_{2} \mathrm{CH}_{2}{ }^{\circ}\right)$ which adds across a double bond of a second propylene molecule to form the hexenyl anion $\left(\mathrm{K}^{+} \mathrm{CH}_{2} \mathrm{CH}_{2} \mathrm{CH}_{2} \mathrm{CH}\left(\mathrm{CH}_{3}\right) \mathrm{CH}_{2}\right)$. Depending on exactly how the carbanion adds across the double bond, 4-methyl-1-pentene or 1-hexene is produced. A variety of transition metal coordination catalysts such as $\mathrm{Cr}, \mathrm{Zr}$, and $\mathrm{V}$ are used in conjunction with an aluminum alkyl cocatalyst to polymerize the monomer to form head-to-tail isotactic polymers. The most active and stereospecific transition metal catalyst is $\mathrm{Ti}$. The most widely used catalyst system consists of $\delta$ - TiCl 3 prepared from the reduction of $\mathrm{TiCl}_{4}$ by 
aluminum alkyls. Polymerization of the monomer with heterogeneous Ziegler-Natta coordination catalysts follows the same general mechanism as the polymerization of ethylene and propylene. The structure of the resulting polymer is shown in Figure 1.

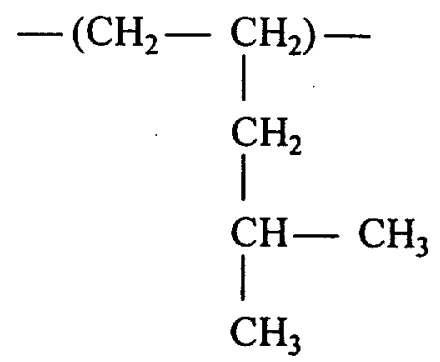

Figure 1. Chemical structure of poly(4-methyl-1-pentene).

Crystallization. PMP is a polymorph, a material that can crystallize in a variety of crystal lattices [1]. Crystallization from the melt results in a single structure known as modification I. This structure (modification I) has a tetragonal unit cell with four chains passing through it. There are 28 repeat units per unit cell. Due to the branched nature of this polymer, the chains are in a $7 / 2$ helical conformation, with the axes of the helices parallel to the c-axis of the unit cell. Five different structures (modifications I, II, III, IV, and V) have been reported for crystallization from semidilute solution. The crystallization behavior of this polymer are summarized in Table 1 . The solvents used for crystallization are summarized in Table 2 .

Table 1. Crystallization of Poly(4-Methyl-1-Pentene)

\begin{tabular}{|l|l|l|l|l|l|l|}
\hline Modification & Unit Cell & $\mathrm{a}(\mathrm{A})$ & $\mathrm{b}(\mathrm{A})$ & $\mathrm{c}(\mathrm{A})$ & Transition & Transition Point \\
\hline $\mathrm{I}$ & Tetragonal & 18.66 & 18.66 & 13.80 & none & most stable \\
\hline II & Tetragonal & 19.16 & 19.16 & 7.12 & $\mathrm{II} \rightarrow \mathrm{I}$ & $82^{\circ} \mathrm{C}$ \\
\hline III & Tetragonal & 19.36 & 19.36 & 6.94 & $\mathrm{III} \rightarrow \mathrm{I}$ & $55-73^{\circ} \mathrm{C}$ \\
\hline IV & Hexagonal & & & 6.5 & $\mathrm{IV} \rightarrow \mathrm{I}$ & $200-270^{\circ} \mathrm{C} \& 4500 \mathrm{~atm}$ \\
\hline $\mathrm{V}$ & Hexagonal & 22.17 & & 6.69 & $\mathrm{~V} \rightarrow \mathrm{I}$ & $130^{\circ} \mathrm{C}$ \\
\hline
\end{tabular}

Table 2. Solvents for Crystallization of Poly(4-Methyl-1-Pentene)

\begin{tabular}{|l|l|l|}
\hline Modification I & Modification III & Modification IV \\
\hline n-nexadecane $195^{\circ} \mathrm{C}$ & n-heptane $135^{\circ} \mathrm{C}$ & cyclopentane $85^{\circ} \mathrm{C}$ \\
\hline m-dodecane $165^{\circ} \mathrm{C}$ & n-pentane $135^{\circ} \mathrm{C}$ & \\
\hline xylene \& amyl acetate $165^{\circ} \mathrm{C}$ & $2,2,4$-trimethylpentene $165^{\circ} \mathrm{C}$ & \\
\hline n-nonane $165^{\circ} \mathrm{C}$ & 3,4 -dimethylhexane $135^{\circ} \mathrm{C}$ & \\
\hline n-octane $165^{\circ} \mathrm{C}(1 \&$ II) & 2,4 -dimethylpentane $165^{\circ} \mathrm{C}$ & \\
\hline & 2,3 -dimethylpentane $165^{\circ} \mathrm{C}$ & \\
\hline & 3 -ethylpentane $165^{\circ} \mathrm{C}$ & \\
\hline & cyclooctane $135 \& 165^{\circ} \mathrm{C}$ & \\
\hline & cycloheptane $85^{\circ} \mathrm{C}$ & \\
\hline & cyclohexane $85^{\circ} \mathrm{C}$ & \\
\hline & carbon tetrachloride $85^{\circ} \mathrm{C}$ & \\
\hline & carbon disulfide $85 \& 135^{\circ} \mathrm{C}$ (III \& II) & \\
\hline & &
\end{tabular}


Physical Properties. As discussed by Lopez and Wilkes, unoriented crystalline isotactic PMP is a rigid thermoplastic with low elongation at break [1]. It has been reported to display a tensile modulus of 0.8 to $1.2 \mathrm{GPa}$ (ASTM D638), tensile strength at yield of $23 \mathrm{MPa}$ (ASTM D638), tensile strength at break of $17 \mathrm{MPa}$ (ASTM D638), and elongation at break of 10-20\% (He \& Porter, 1987; Kissin, 1987). This polymer is more brittle than high-density polyethylene due to the higher molecular cross-sectional area $\left(85.4 \times 10^{-20} \mathrm{~m}^{2}\right.$ for PMP vs. $19.3 \times 10^{-20} \mathrm{~m}^{2}$ for HDPE). The critical tensile strength of a polymer decreases the number of backbone bonds per unit crosssectional area decrease. The plastic deformation of PMP single crystals under uniaxial extension is attributed to micronecking, lateral buckling, localized lamellar thinning, and a unique slip mechanism that causes sectorization of the crystals. The deformation process of PMP upon tensile yielding produces whitening or crazing of material that has been found to be porous. PMP samples swollen with benzene have exhibited elongations as great as 480 percent. 'Such swelling phenomena appears to be reversible. The specific volumes of both crystalline and amorphous PMP increase with temperature (Figure 13 of Reference [1]). Several quantitative physical properties of PMP have been summarized by Lopez and Wilkes and are given in Table 3.

Table 3. Properties of Poly(4-Methyl-1-Pentene)

\begin{tabular}{|l|l|l|l|}
\hline Property & Units & Value & Reference \\
\hline Crystalline Density $\left(20^{\circ} \mathrm{C}\right)$ & $\mathrm{g} \mathrm{cm}^{-3}$ & 0.828 & Griffith \& Ranby, 1960 \\
\hline Amorphous Density $\left(20^{\circ} \mathrm{C}\right)$ & $\mathrm{g} \mathrm{cm}^{-3}$ & 0.838 & Isaacson, Kirshenbaum, \& Feist, 1964 \\
\hline Heat of Fusion & $\mathrm{kJ} \mathrm{mol}^{-1}$ & $5.5-10$ & Karasz et al. 1967; Charlet et al. 1988 \\
\hline Melting Point & ${ }^{\circ} \mathrm{C}$ & 245 & Karasz, Bair, \& O' Reilly, 1967 \\
\hline Glass Transition Point & ${ }^{\circ} \mathrm{C}$ & $18-65$ & \\
\hline Specific Heat Capacity $\left(25^{\circ} \mathrm{C}\right)$ & $\mathrm{J} \mathrm{g}^{-1} \mathrm{~K}^{-1}$ & 1.757 & Charlet \& Delmas, 1988 \\
\hline Thermal Conductivity $\left(25^{\circ} \mathrm{C}\right)$ & $\mathrm{mW} \mathrm{cm} \mathrm{K}^{-1}$ & 1.72. & Jain, Wunderlich, \& Chaubey, 1977 \\
\hline Tensile Modulus & $\mathrm{GPa}$ & $0.8-1.2$ & Zoller, Starkweather, \& Jones, 1986 \\
\hline Tensile Strength at Yield & $\mathrm{MPa}$ & $23-28$ & Schaefgen, 1959 \\
\hline Tensile Strength at Break & $\mathrm{MPa}$ & $17-20$ & Mandelkern, 1964 \\
\hline Elongation at Break & $\%$ & $10-25$ & Mandelkern, 1964 \\
\hline Notched Impact Strength & $\mathrm{kJ} \mathrm{m}$ & $100-200$ & Mandelkern, 1964 \\
\hline Refractive Index $\left(17^{\circ} \mathrm{C}\right)$ & none & 1.46 & Hasegawa et al. 1970 \\
\hline Dielectric Constant $\left(25^{\circ} \mathrm{C} \mathrm{\&} \mathrm{30-100} \mathrm{Hz)}\right.$ & none & 2.1 & Woodward, Sauer, \& Wall, 1961 \\
\hline
\end{tabular}

As explained by Rossen, dynamic mechanical testing can be used to gain insight into the viscoelastic properties of polymers [2]. A sinusoidal strain, $\gamma=\gamma^{\prime} \sin (\omega t)$, is applied to the polymer and the resulting sindusoidal stress, $\tau=\tau^{\prime} \sin (\omega t+\delta)$, is measured. In the case of purely elastic materials, the stress and strain are in phase $\left(\delta=0^{\circ}\right)$. In the case of purely viscous materials, the stress and strain are in quadrature $\left(\delta=90^{\circ}\right)$. If the material is viscoelastic, the phase angle lies between 0 and 90 degrees. Note that the strain and stress can also be written in phasor notation: $\gamma^{*}=\gamma^{\prime}+\mathrm{i} \gamma^{\prime \prime}$ and $\tau *=\tau^{\prime}+\mathrm{i} \tau^{\prime \prime}$, respectively. Furthermore, note that the complex strain and stress are related by the complex modulus, $G^{*}=G^{\prime}+i G^{\prime \prime}$, where $G^{\prime}$ is the storage modulus and $G^{\prime \prime}$ is the loss modulus. The physical significance of the loss tangent can be best understood by defining it in terms $G^{\prime}$ and $G^{\prime \prime}$. 
$\tan (\delta)=\frac{\tau^{\prime \prime}}{\tau^{\prime}}=\frac{G^{\prime \prime}}{G^{\prime}}$

From this definition, it is evident that the loss tangent is the ratio of mechanical energy converted to heat by molecular friction (represented by $G^{\prime \prime}$ ) to mechanical energy stored elastically in the material (represented by $G^{\prime}$ ). The loss tangent can also be defined in terms of the complex viscosity, $\eta=\eta^{\prime}+\mathrm{i} \eta^{\prime \prime}$.

$\tan (\delta)=\frac{\tau^{\prime \prime}}{\tau^{\prime}}=\frac{\eta^{\prime \prime}}{\eta^{\prime}}$

The loss tangent is measured as a function of temperature during a typical experiment. Peaks in loss tangent at characteristic temperature levels are referred to as "relaxation peaks" and are indicative of the absorption of mechanical energy from the surroundings.

The viscoelastic properties of PMP have been investigated over a wide range of frequencies: torsional pendulum measurements at $10^{-3}$ to $10 \mathrm{~Hz}$; dynamic extensional testing at $110 \mathrm{~Hz}$; dielectric measurements at $10^{5} \mathrm{~Hz}$; and ultrasonic measurements at $10^{6} \mathrm{~Hz}[1]$. The three characteristic relaxation peaks for PMP, $\alpha_{a}, \alpha_{c}$, and $\beta_{s c}$, are summarized in Table 4.

Table 4. Relaxation Peaks for Poly(4-Methyl-1-Pentene)

\begin{tabular}{|l|l|l|l|}
\hline Relaxation Peak & Peak Temp. $\left({ }^{\circ} \mathrm{C}\right)$ & $\begin{array}{l}\text { Frequency } \\
(\mathrm{Hz})\end{array}$ & Comments \\
\hline High-temperature peak $\left(\alpha_{2}\right)$ & $40 ; 52-67$ & $90 ; \leq 10$ & Associated with $\mathrm{T}_{\mathrm{g}}$ \\
\hline High-temperature peak $\left(\alpha_{\mathrm{c}}\right)$ & 140 & 90 & Expansion of unit cell a-parameter \\
\hline Low-temperature peak $\left(\beta_{\mathrm{sc}}\right)$ & $-140 ;-123$ & $90 ; \leq 10$ & Localized thermal motion of side chain \\
\hline
\end{tabular}

The first high-temperature peak $\left(\alpha_{\mathrm{a}}\right)$ coincides with the glass transition temperature and has an activation energy of about $443 \mathrm{~kJ} / \mathrm{mol}$. The second high-temperature peak $\left(\alpha_{\mathrm{c}}\right)$ is attributed to expansion of the unit cell a-parameter. The low-temperature peak $\left(\beta_{\mathrm{sc}}\right)$ is believed to be due to localized thermal (rotational and vibrational) motion of the side chain.

\section{Kinetics of Thermal Oxidative Degradation}

As described by Zitomer and DiEdwardo, PMP is a crystalline, saturated polyhydrocarbon with pendant isobutyl groups on alternate carbon atoms along the polymer chain [3]. The thermal oxidation of this polymer is interesting because there are two potential sites for attack. the tertiary carbon on the polymer backbone and the tertiary carbon in the pendant isobutyl group. It is difficult to predict which of the two sites is more susceptible to oxidation since their electron environments are similar. According to El Naggar, Lopez, and Wilkes, PMP is "highly prone to degradation by high-energy irradiation" due to the presence of two tertiary carbon atoms per repeat length [4]. Tertiary carbon atoms are more susceptible to radiation-induced degradation than secondary carbon atoms. 
Zitomer and DiEdwardo used mass spectrometry, thermogravimetry, and gas chromatography to study the thermal oxidation of atactic and isotactic PMP in air [3]. The rate of carbonyl ingrowth was determined from infrared (IR) spectra of samples oxidized for various periods of time at several temperature levels $\left(160,175,190,198,210\right.$, and $\left.215^{\circ} \mathrm{C}\right)$. From this data the activation energy for carbonyl formation, $E_{A}$, was determined to be $20.1 \mathrm{kcal} \mathrm{mol}^{-1}$, which is very reasonable. During thermal gravimetric analysis (TGA), the observed weight loss accelerated dramatically as the temperature increased above $300^{\circ} \mathrm{C}$. The material was completely volatilized at $410^{\circ} \mathrm{C}$. The analysis of weight loss data at 160,190 , and $220^{\circ} \mathrm{C}$ gave an activation energy of $21.5 \mathrm{kcal} \mathrm{mol}^{-1}$ for the simultaneous formation of volatile products (VPs).

Stivala and Gabbay used thermogravimetric analysis to conduct detailed studies of the thermal oxidation of atactic and isotactic PMP [5]. Weight loss was measured as a function of time at various temperatures $\left(125,140,145,155,165,175\right.$, and $\left.185^{\circ} \mathrm{C}\right)$ and oxygen concentrations $(75$, 87.5 , and $100 \% \mathrm{O}_{2}$ ). These authors give the following expression (Equation 3 ) for the rate of volatile product formation:

$\frac{d[V P]}{d t}=\frac{k_{6} k_{1} k_{3}[R H]\left(1-e^{-t}\right)\left[O_{2}\right]}{\left(k_{3}-k_{4}\right) A}=C\left[O_{2}\right]$

where $[\mathrm{RH}]$ is the concentration of polymer, $\left[\mathrm{O}_{2}\right]$ is the concentration of oxygen, $\mathrm{k}_{\mathrm{i}}$ is a particular kinetic rate constant, and both $\mathrm{A}$ and $\mathrm{C}$ are constants under specific conditions. In this case, the rate expression is assumed to be first order in both polymer and oxygen concentration. Provided that $[\mathrm{RH}]$ and $\mathrm{e}^{-\mathrm{t}}$ remain unchanged, a linear relationship exists between $\mathrm{d}[\mathrm{VP}] / \mathrm{dt}$ and $\left[\mathrm{O}_{2}\right]$. The rate of volatile product formation can also be expressed as:

$\frac{d[V P]}{d t}=\rho_{m} \frac{2 k_{5}}{k_{6}}$

where $\rho_{\mathrm{m}}$ is the maximum rate of carbonyl formation. The expression for $\rho_{\mathrm{m}}$ is:

$\rho_{m}=\frac{k_{6} k_{1} k_{3}[R H]\left(1-e^{-t_{m}}\right)\left[O_{2}\right]}{\left(k_{3}-k_{4}\right) A}$

where $t_{m}$ is the time to reach $\rho_{m}$. The kinetic rate constants determined by Stivala and Gabbay are summarized in Table 5 .

In this paper, we provide another analysis of the data collected by Stivala and Gabbay [5]. The rate expression for volatile products, $d[\mathrm{VP}] / \mathrm{dt}$, is assumed to have a first-order dependence on polymer concentration, but an $\mathrm{n}$-order dependence on oxygen concentration.

$\frac{d[V P]}{d t}=A e^{-\frac{l_{1}}{k T}}[R H]\left[O_{2}\right]^{n}$ 
Table 5. Kinetic Parameters from Stivala and Gabbay

\begin{tabular}{|c|c|c|c|c|c|c|}
\hline $\mathrm{T}\left({ }^{\circ} \mathrm{C}\right)$ & $\mathrm{k}_{5} \times 10^{9}(\mathrm{l})$ & $\mathrm{k}_{6} \times 10^{6}(1)$ & {$\left[\mathrm{O}_{2}\right] \%$} & $\rho_{\mathrm{m}}(1)$ & $2 \mathrm{k}_{5} \mathrm{P}_{\mathrm{m}} / \mathrm{k}_{6} \times 10^{3}$ & $\mathrm{~d}[\mathrm{VP}] / \mathrm{dt} \times 10^{3}(2)$ \\
\hline 155 & 0.20 & 0.147 & 100 & 0.560 & 1.5 & 1.3 \\
\hline & & & 87.5 & 0.520 & 1.0 & 1.0 \\
\hline & & & 75 & 0.480 & 1.3 & 0.9 \\
\hline & & & & & & \\
\hline 165 & 0.30 & 0.208 & 100 & 0.780 & 2.2 & 2.8 \\
\hline & & & 87.5 & 0.730 & 2.1 & 2.3 \\
\hline & & & 75 & 0.690 & 1.9 & 2.2 \\
\hline 175 & 0.70 & 0.366 & 100 & 1.030 & 3.9 & 4.4 \\
\hline & & & 87.5 & 0.961 & 3.6 & 3.8 \\
\hline & & & 75 & 0.90 & 3.4 & 3.0 \\
\hline & & & & & & \\
\hline 185 & 1.20 & 0.428 & 100 & 1.420 & 8.0 & 10.8 \\
\hline & & & 87.5 & 1.340 & 7.5 & 9.5 \\
\hline & & & 75 & 1.260 & 7.0 & 8.0 \\
\hline
\end{tabular}

Note: (1) infrared data for non-volatile products; (2) TGA data for volatile products.

As done in the analysis by Stivala and Gabbay, it is assumed that the following relationships (Equations 7 and 8) exist between the time-dependent concentrations of volatile products and polymer, the time-dependent fractional weight loss of the polymer, $w$, and the initial concentration of polymer, $[\mathrm{RH}]_{0}$ :

$$
\begin{aligned}
& {[\dot{V P}]=w \times[R H]_{0}} \\
& {[R H]=(1-w) \times[R H]_{0}}
\end{aligned}
$$

The rate expression (Equation 6) can be rewritten in terms of fractional weight loss:

$$
\frac{d w}{d t}=A e^{-\frac{E_{1}}{R T}}(1-w)\left[O_{2}\right]^{n}
$$

Integration of this simple rate expression (Equation 9) gives:

$$
\frac{\ln \left(\frac{1}{1-w}\right)}{\Delta t}=A e^{-\frac{E_{1}}{R T}}\left[O_{2}\right]^{n}
$$

This integrated rate expression (Equation 10) can be linearized.

$$
\ln \left\{\frac{\ln \left(\begin{array}{c}
1 \\
1-w
\end{array}\right)}{\Delta t}\right\}=\ln (A)+n \ln \left(\left[O_{2}\right]\right)-\frac{E_{A}}{R} \frac{1}{T}
$$


Linearization of this expression enables multivariable linear regression of the data presented in Table 1 of Reference [5].

$$
\ln \left\{\frac{\ln \left(\begin{array}{c}
1 \\
1-w
\end{array}\right)}{\Delta t}\right\}=24.898+2.1818 \times \ln \left(\left[O_{2}\right]\right)-13,486 \frac{1}{T}
$$

The regression gave a very high regression coefficient $(r=0.93129)$ and indicates a second order dependence on oxygen concentration. Recall that the original analysis done by Stivala and Gabbay assumed first-order dependence on oxygen concentration (Table 5). This empirical expression for weight loss in PMP was used to calculate the curves shown in Figures 1 and 2. From these calculations, it is evident that there will be relatively little weight loss in PMP held in air at $300 \mathrm{~K}$ for sixty years. However, the weight loss at $325 \mathrm{~K}$ will become noticeable $(6 \%)$ over this period of time. The weight loss at $350 \mathrm{~K}$ will be catastrophic (72\%) over sixty years. At $375 \mathrm{~K}$, the degradation of PMP will be almost instantaneous (24\% weight loss after one year). The formation of volatile products and associated weight loss can be prevented by storage of PMP, also known as TPX, at low temperature $(\leq 300 \mathrm{~K})$ and under an atmosphere of inert gas (helium or argon).

In another publication, Babbay, Stivala, and Reich discuss the thermal oxidative degradation of atactic and isotactic PMP powders in the presence of pure, dry oxygen at 145 and $175^{\circ} \mathrm{C}[6,7]$. The formation of nonvolatile products (NVPs) were studied with infrared (IR) spectroscopy, while gas chromatography with mass spectroscopy (GCMS) was used to identify volatile products (VPs). A number of distinctive bands appeared in the infrared spectra of isotactic PMP during oxidation at $145^{\circ} \mathrm{C}$. The appearance of a strong band centered at a wavelength of $2.85 \mu \mathrm{m}$ is indicative of the formation of hydroxyl groups. The appearance of a triplet in the carbonyl stretching region $(5.70-5.85 \mu \mathrm{m})$ is indicative of the formation of aldehyde, ketone, and carboxylic acid functional groups. The appearance of a band centered at $11.35 \mu \mathrm{m}$ is indicative of the formation of substituted vinylidene double bonds. Corresponding GCMS data revealed a number of consistent volatile products: carbon dioxide; acrolein; acetaldehyde; acetone; isobutyraldehyde; methanol; ethanol; isopropanol; crotonaldehyde; water; isovaleraldehyde; isobutanol; acetic acid; propionic acid; isobutyric acid; and oxalic acid; isovaleric acid. Species present in the greatest abundance were: carbon dioxide $(47 \%)$; water and isovaleraldehyde (16\%); isobutyraldehyde (14\%); and acetic acid (5\%). Data for atactic PMP is similar. Particular attention should be given to acetic acid since it can promote metallic corrosion. A detailed kinetic mechanism is presented that explains formation of the observed degradation products. This mechanism is based on a series of chain reactions that involve the following free radicals: $\mathrm{R} ; \mathrm{HO}_{2}{ }^{\circ}, \mathrm{RO}_{2}{ }^{\circ}, \mathrm{RO}^{\circ}$, and $\mathrm{HO}^{\circ}$. It is noteworthy that the infrared data of Gabbay, Stivala, and Reich $[6,7]$ are completely consistent with the earlier results obtained by Zitomer and DiEdwardo [2]. 
Gabbay and Stivala have also published detailed interpretations of the infrared spectra of PMP [8]. Interesting studies of the infrared absorption of PMP have been conducted by Chantry et al. [9] and may be of interest to the reader.

\section{Radiation-Induced Degradation}

High-energy radiation can cause chain scission and crosslinking in polymers, thereby altering their chemical and physcial properties. The effects neutrons and $\gamma$-rays on the optical clarity of PMP over the range of wavelength from 0.23 to $2.0 \mathrm{~nm}$ was investigated by Eberhagen and Fahrbach [10]. They found that this material retained optical clarity at doses up to $100 \mathrm{Mrad}$. Photobleachable species due to g-irradiation were detected with electron spin resonance (ESR) spectroscopy by Kimura, Ueda, and Hirai [11]. El Naggar, Lopez, and Wilkes have studied the effects of high-energy electron beams on both high- and low-molecular weight PMP, HMPMP and LMPMP, respectively [4]. The molecular weights were $1.8 \times 10^{6}$ and $9.2 \times 10^{5}$, respectively. Samples were irradiated at $40 \mathrm{Mrad}$ or less in nitrogen or air. First, these authors found that the molecular weight of the polymer systematically decreases with increasing dose. The molecular weight of HMPMP decreased from $1.8 \times 10^{6}$ to less than $4.2 \times 10^{4}$ after a $40 \mathrm{Mrad}$ dose. Furthermore, they found that oxidative degradation is enhanced by radiation-induced chain scission. Tensile testing revealed that irradiation systematically decreases "elongation at break." As shown in Figure 3, non-irradiated LMPMP samples broke at an elongation of 22 to $32 \%$, whereas samples irradiated at $40 \mathrm{Mrad}$ broke at an elongation of less than $2 \%$. Non-irradiated HMPMP samples broke at an elongation of 46 to $49 \%$, whereas samples irradiated at $40 \mathrm{Mrad}$ broke at an elongation of less than $3 \%$. The effect of irradiation on the "stress at break" was also studied (Figure 3). At doses up to $20 \mathrm{Mrad}$, electron beam irradiation appears to slightly increase the strength of both LMPMP and HMPMP. This enhancement is attributed to radiation-induced cross-linking in the polymer. The "stress at break" was between 17 and $27 \mathrm{MPa}$ for all samples irradiated at doses $\leq 20 \mathrm{Mrad}$. However, as the dose is increased to $40 \mathrm{Mrad}$, chain-scission dominated and the strength was degraded. The "stress at break" was between 10 and $20 \mathrm{MPa}$ for all samples irradiated at a dose of $40 \mathrm{Mrad}$. The beneficial effects of irradiation at doses below $20 \mathrm{Mrad}$ were enhanced by avoiding oxygen, while the detrimental effects or irradiation at 40 Mrad were exacerbated by the presence of oxygen. The relative effect of irradiation on "elongation at break" was greater than the relative effect of irradiation on "stress at break." As shown in Figure 4, the melting and recrystallization temperatures of non-irradiated, HMPMP samples were $239-240$ and $202-204^{\circ} \mathrm{C}$, respectively. Irradiation systematically decreased the melting and recrystallization temperatures to about $221-222$ and $189^{\circ} \mathrm{C}$, respectively. The enthalpies of fusion $\left(\Delta \mathrm{H}_{f}\right)$ and recrystallization $\left(\Delta \mathrm{H}_{\mathrm{c}}\right)$ of non-irradiated, high molecular weight samples were approximately 13.2 and $14.5 \mathrm{cal} \mathrm{g}^{-1}$, respectively. These values dropped to about 11.5 and $11 \mathrm{cal} \mathrm{g}^{-1}$, respectively, after irradiation at $40 \mathrm{Mrad}$.

The effects of both $\gamma$-ray and electron beam irradiation on "elongation at break" and "chemiluminescence intensity" have been studied by Yoshi et al. [12]. 'A ${ }^{60} \mathrm{Co}$ source was used to irradiate PMP samples at a rate of $1 \mathrm{Mrad} \mathrm{h}^{-1}$. A Cockroft-Walton accelerator produced 1 $\mathrm{MeV}$ electrons at a current of $1 \mathrm{~mA}$. PMP samples were given a $1 \mathrm{Mrad}$ dose per pass through the electron beam ( $\left.0.143 \mathrm{Mrad} \mathrm{s}^{-1}\right)$. As shown in Figure 5, PMP samples irradiated with $\gamma$-rays 
are more prone to degradation than those irradiated with electron beams. For example, the "elongation at break" dropped from $80 \%$ to $32 \%$ after $\gamma$-irradiation at $10 \mathrm{Mrad}$. An equivalent dose of electrons reduced the "elongation at break" to only $56 \%$. Furthermore, $\gamma$-rays produced more chemiluminescence than electrons. Chemiluminescence (CL) is attributed to photons emitted from excited ketones that are formed by peroxy radicals in the termination step of a freeradical chain reaction. As expected, the rate of formation of the excited ketones and the related $\mathrm{CL}$ intentsity increases with temperature.

\section{Summary}

From a detailed quantitative analysis of published data, it is evident that relatively little weight loss will occur in PMP (TPX) stored in air at $300 \mathrm{~K}$ for sixty years. However, the weight loss at $325 \mathrm{~K}$ will be noticible $(6 \%)$ over this period of time. The weight loss at $350 \mathrm{~K}$ will be catastrophic (72\%) over sixty years. At $375 \mathrm{~K}$, the degradation of PMP will be almost instantaneous ( $24 \%$ weight loss after one year). Volatile products include: carbon dioxide; acrolein; acetaldehyde; acetone; isobutyraldehyde; methanol; ethanol; isopropanol; crotonaldehyde; water; isovaleraldehyde; isobutanol; acetic acid; propionic acid; isobutyric acid; and oxalic acid; isovaleric acid. Species expected to be present in the greatest abundance are: carbon dioxide; water and isovaleraldehyde; isobutyraldehyde; and acetic acid. Several of these expected volatile products are capable of promoting corrosion of metallic components. The formation of volatile products and associated weight loss can be prevented by storage of PMP at low temperature $(\leq 300 \mathrm{~K})$ and/or under an atmosphere of inert gas (helium or argon).

Irradiation of PMP with electrons and $\gamma$-rays reduces molecular weight, promotes chain scission and oxidative degradation, and causes the material to become brittle. Irradiation with $\gamma$-rays is more damaging that irradiation with electron beams. The molecular weight of HMPMP decreased from $1.8 \times 10^{6}$ to less than $4.2 \times 10^{4}$ after a $40 \mathrm{Mrad}$ dose of electrons. Corresponding changes in the melting and recrystallization temperatures are observed. Tensile testing revealed that irradiation systematically decreases "elongation at break." Non-irradiated LMPMP samples broke at an elongation of 22 to $32 \%$, whereas samples irradiated at $40 \mathrm{Mrad}$ broke at an elongation of less than $2 \%$. Non-irradiated HMPMP samples broke at an elongation of 46 to $49 \%$, whereas samples irradiated at $40 \mathrm{Mrad}$ broke at an elongation of less than $3 \%$. At doses up to $20 \mathrm{Mrad}$. electron beam irradiation appears to slightly increase the strength of both HMPMP and LMPMP. This enhancement is attributed to radiation-induced cross-linking in the polymer. The "stress at break" was between 17 and $27 \mathrm{MPa}$ for all samples irradiated at doses $\leq 20 \mathrm{Mrad}$. However, as the dose is increased to $40 \mathrm{Mrad}$, chain-scission dominated and the strength was degraded. The "stress at break" was between 10 and $20 \mathrm{MPa}$ for all samples irradiated at a dose of $40 \mathrm{Mrad}$. The beneficial effects of irradiation at doses below $20 \mathrm{Mrad}$ were enhanced by avoiding oxygen, while the detrimental effects or irradiation at $40 \mathrm{Mrad}$ were exacerbated by the presence of oxygen. Some loss in the "stress at break" is also observed. Irradiation with $\gamma$-rays is more damaging that irradiation with electron beams. For example, the "elongation at break" dropped from $80 \%$ to $32 \%$ after $\gamma$-irradiation at $10 \mathrm{Mrad}$. An equivalent dose of electrons reduced the "elongation at break" to only 56\%. Other references are also recommended [13-15]. 


\section{Acknowledgments}

The help and insight of Jim Tyler, Jim Hanafee, and Sue Taylor are gratefully acknowledged. This work was done under the auspices of the U.S. Department of Energy (DOE) by Lawrence Livermore National Laboratory (LLNL) under Contract No. W-7405-Eng-48.

\section{References}

1. L. C. Lopez, G. L. Wilkes, P. M. Stricklen, S. A. White, "Synthesis, Structure, and Properties of Poly(4-Methyl-1-Pentene)," Journal of Macromolecular Science, Review of Macromolecular Chemical Physics, Ser. C, Vol. 32, No. 3 \& 4, p. $301-406,1992$.

2. S. L. Rosen, "Linear Viscoelasticity," Chapter XVIII, Fundamental Principles of Polymeric Materials, 2nd Ed., John Wiley and Sons, New York, NY, pp. 298-349, 1993.

3. F. Zitomer, A. H. DiEdwardo, "Degradation Kinetics and Mechanisms of Polymers Using Thermal Spectrometric Techniques," Journal of Macromolecular Science, Chemistry, Ser. A, Vol. 8, No. 1, pp. 119-133, 1974.

4. A. M. El-Naggar, L. C. Lopez, G. L. Wilkes, "Effect of Electron Beam Radiation on the Mechanical and Thermal Properties of Poly(4-Methylpentene-1)," Journal of Applied Polymer Science, Vol. 39, pp. 427-446, 1990.

5. S. S. Stivala, S. M. Gabbay, "Kinetics of the Thermal Oxidation of Poly(4-Methyl-1Pentene) from Volatile Products Using Thermogravimetric Analysis," Polymer, Vol. 18, pp. 807-809, 1977.

6. S. M. Gabbay, S. S. Stivala, L. Reich, "Thermal Oxidative Degradation of Poly(4-Methyl-1Pentene). I. Identification of Products and Mechanisms," Journal of Applied Polymer Science, Vol. 19, pp. 2391-2402, 1975.

7. S. M. Gabbay, S. S. Stivala, "Kinetics of the Thermal Oxidation of Poly(4-Methyl-1Pentene)," Polymer, Vol. 17, pp. 137-141, 1976.

8. S. M. Gabbay, S. S. Stivala, "Infrared Study of Poly(1-Pentene) and Poly(4-Methyl-1Pentene)," Polymer, Vol. 17, pp. 121-124, 1976.

9. G. W. Chantry, J. W. Fleming, P. M. Smith, M. Cudby, H. A. Willis, "Far Infrared and Millimetre-Wave Absorption Spectra of Some Low-Loss Polymers," Chemical Physics Letters, Vol. 10, No. 4, pp. 473-477, 1971.

10. A. Eberhagen, H. U. Fahrbach. International Journal of Infrared Millimeter Waves, Vol. 3, No. 3, p. 297, 1982.

11. T. Kimura, Y. Ueda, Y. Hirai, Canadian Journal of Chemistry, Vol. 64, p. 695, 1986. 
Thermal Oxidative Degradation of Poly(4-Methyl-1-Pentene) - TPX

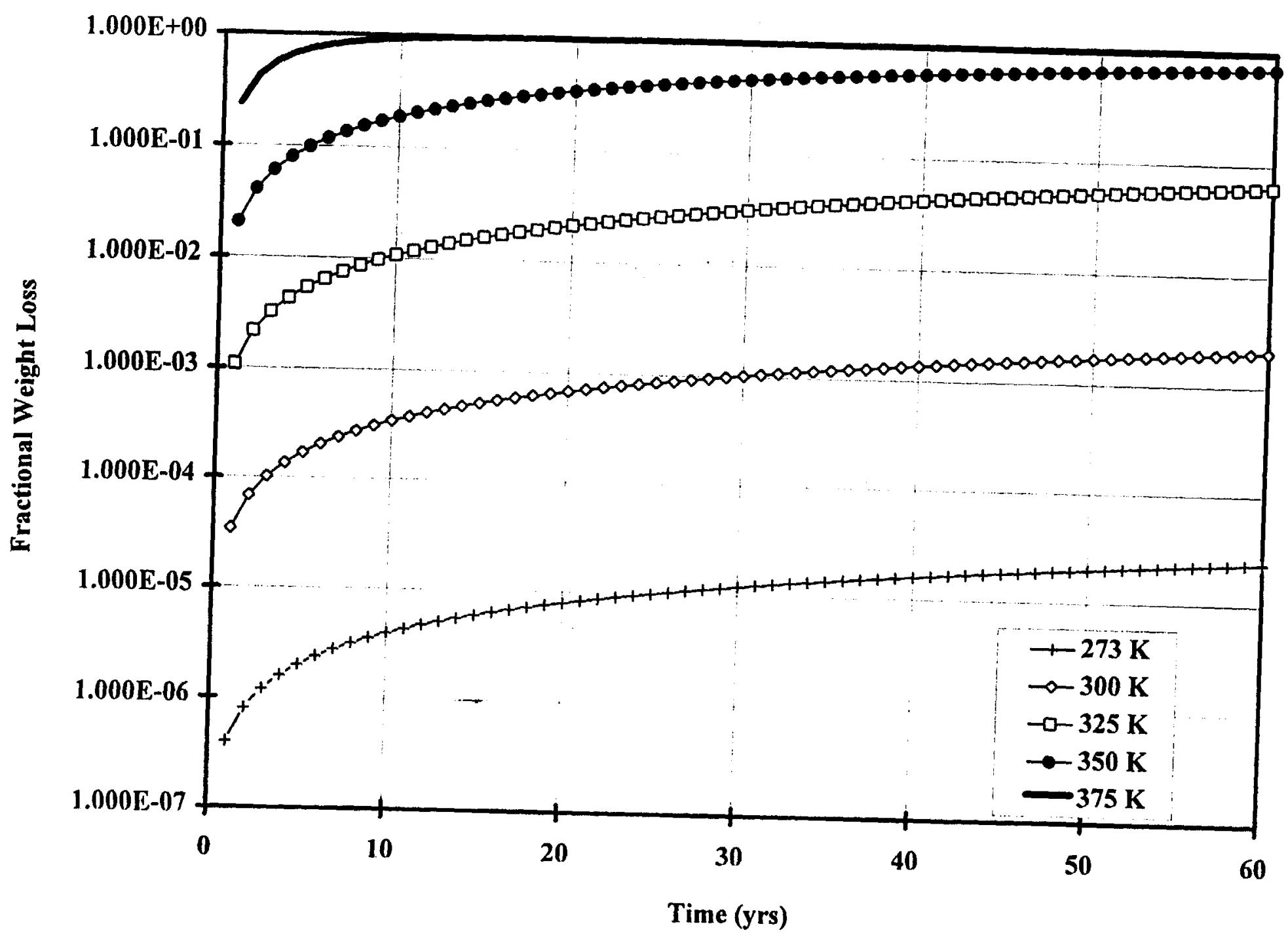

Figure 1 
Thermal Oxidative Degradation of Poly(4-Methyl-1-Pentene) - TPX

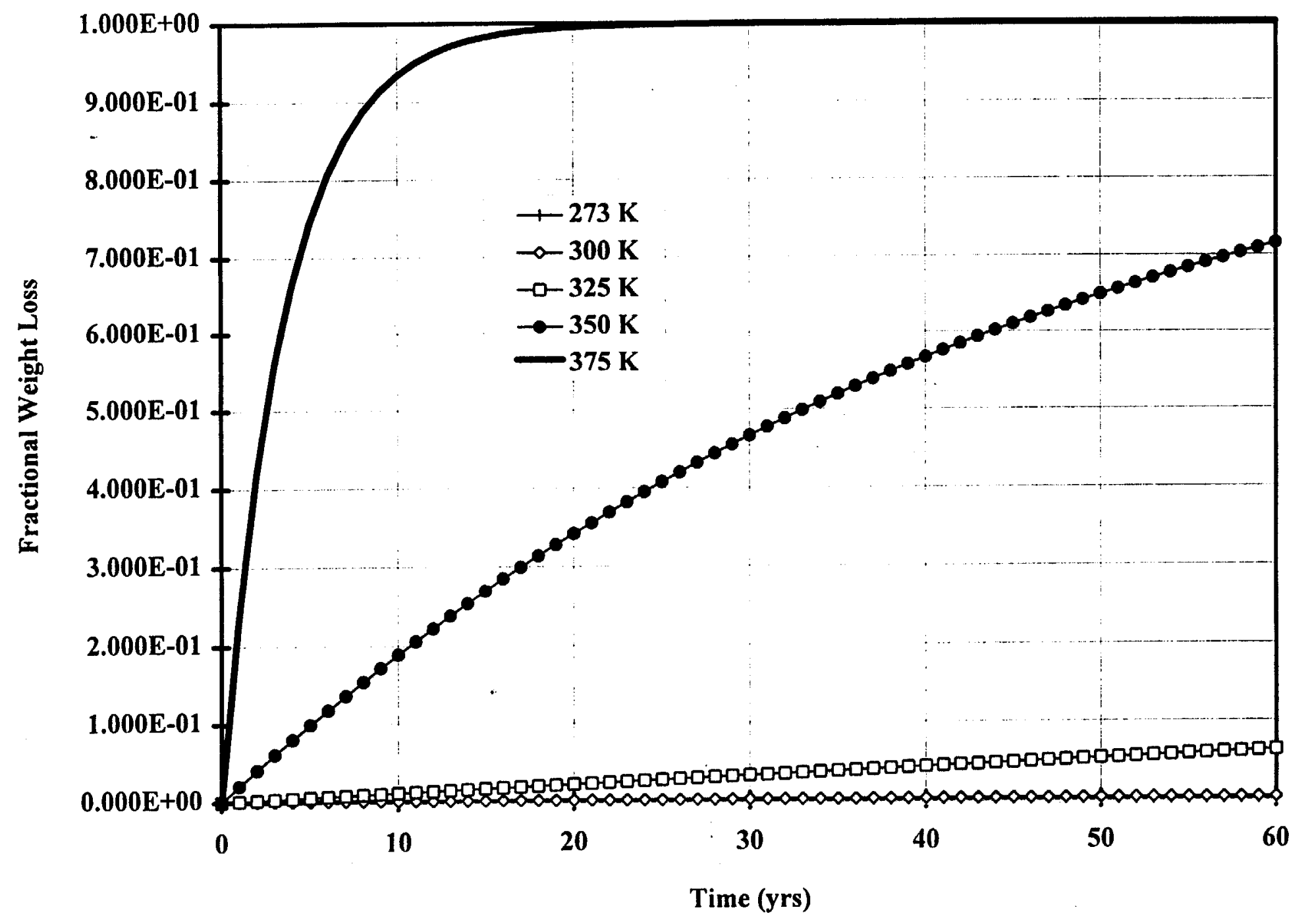

Figure 2 
Effect of EB Radia ion on Poly(4-Methyl-1-Pen ene) - TPX

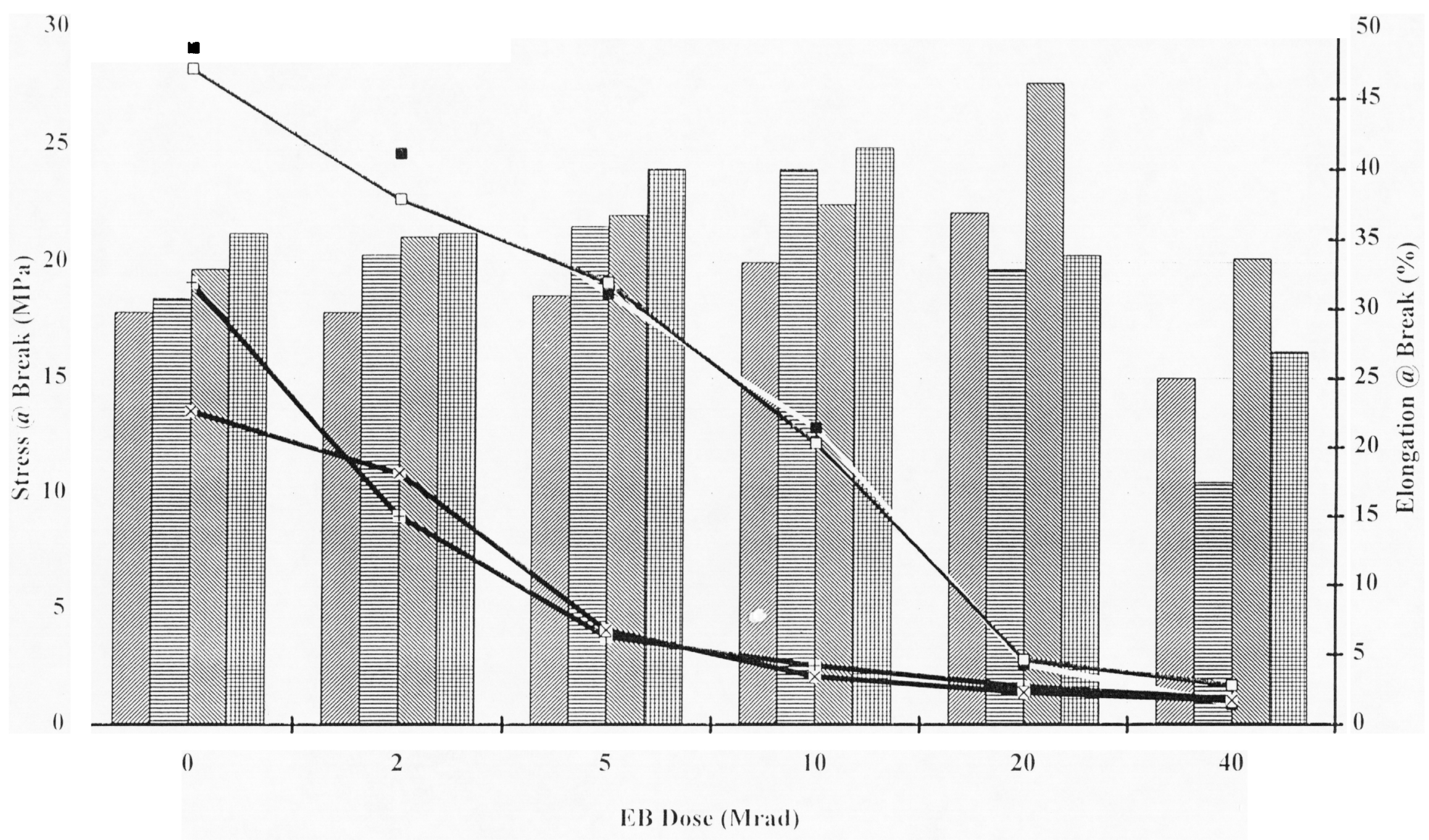

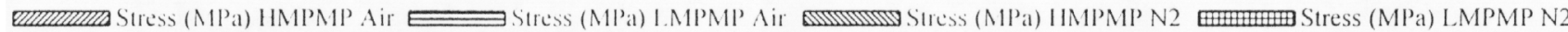

- Strain (\%) HMPMPAir Strain (\%) LMPNPAir Strain (\%) IIMPMPN2 
Effect of EB Radiation on Poly(4-Methyl-1-Pentene) - TPX

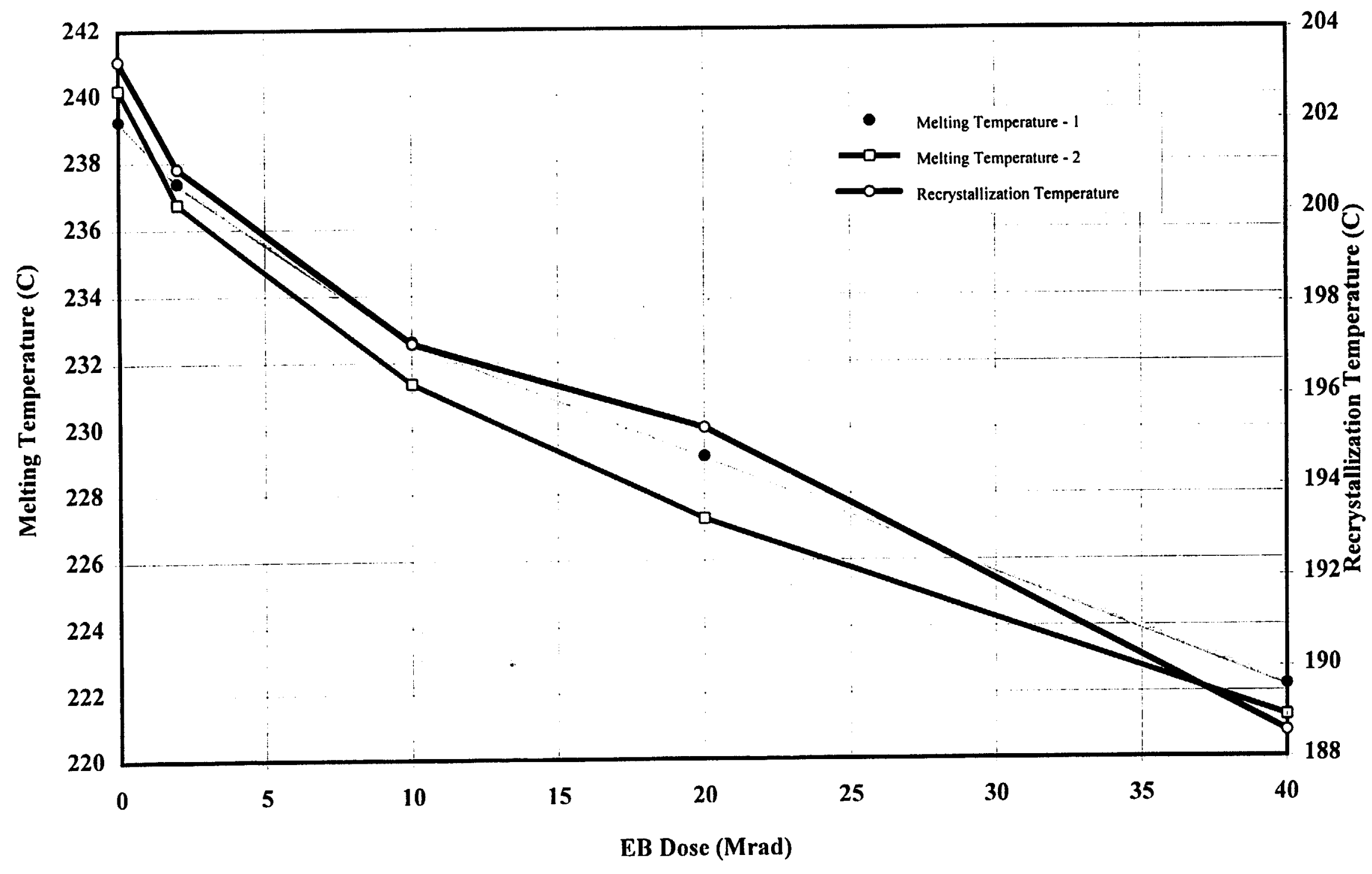

Figure 4 
Effect of Gamma \& Electron Beam Radiation on Poly(4-Methyl-1-Pentene) - TPX

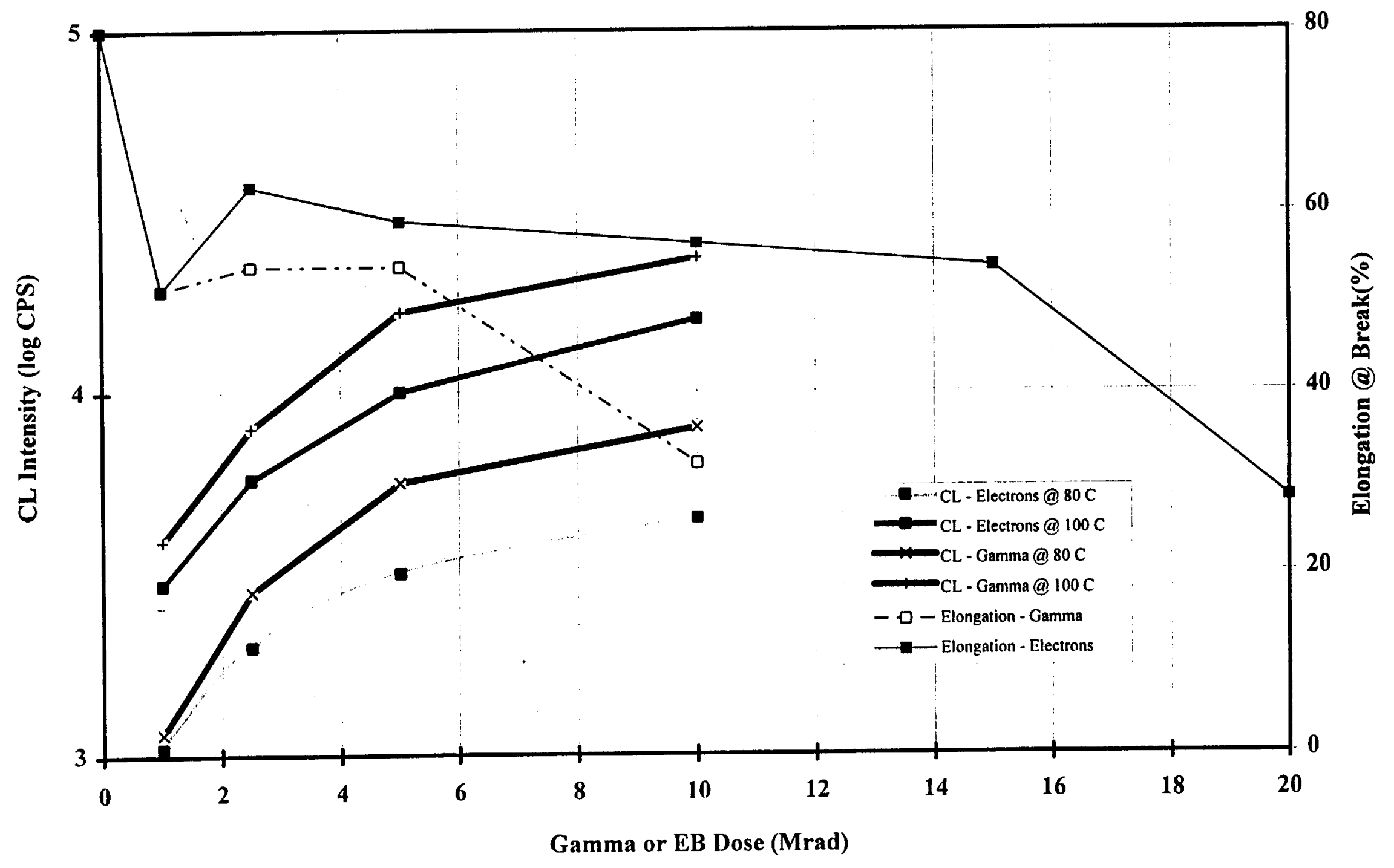

Figure 5 


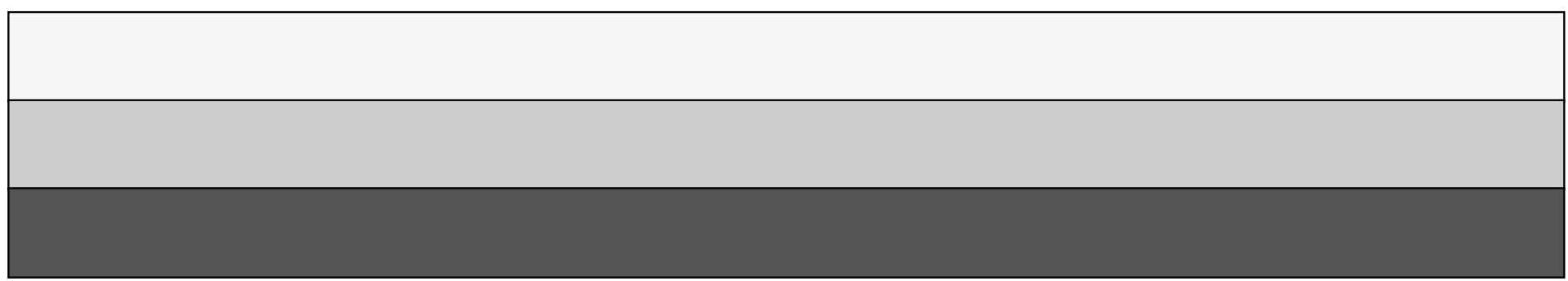

